\title{
Article \\ Quali-Quantitative Study on Phenol Compounds as Early Predictive Markers of Graft Incompatibility: A Case Study on Chestnut (Castanea spp.)
}

\author{
Giovanni Gamba ${ }^{1,2, * \mathbb{D}}$, Viviana Cisse ${ }^{1}$, Dario Donno ${ }^{1,2} \mathbb{D}$, Zoarilala Rinah Razafindrakoto ${ }^{3}$ \\ and Gabriele Loris Beccaro ${ }^{1,2}$ D
}

1 Dipartimento di Scienze Agrarie, Forestali e Alimentari, Università degli Studi di Torino, 10095 Grugliasco, TO, Italy; viviannika01@gmail.com (V.C.); dario.donno@unito.it (D.D.); gabriele.beccaro@unito.it (G.L.B.)

2 Centro Regionale di Castanicoltura del Piemonte, Regione Gambarello 23, 12013 Chiusa di Pesio, CN, Italy

3 Institut Malgache de Recherches Appliquées, P.O. Box 3833, Antananarivo 101, Madagascar; miarotsoa@gmail.com

* Correspondence: giovanni.gamba@unito.it; Tel.: +39-011-670-3158

check for

updates

Citation: Gamba, G.; Cisse, V.;

Donno, D.; Razafindrakoto, Z.R.; Beccaro, G.L. Quali-Quantitative Study on Phenol Compounds as Early Predictive Markers of Graft Incompatibility: A Case Study on Chestnut (Castanea spp.). Horticulturae 2022, 8, 32. https://doi.org/ $10.3390 /$ horticulturae 8010032

Academic Editor: Daniela Farinelli

Received: 6 December 2021

Accepted: 22 December 2021

Published: 29 December 2021

Publisher's Note: MDPI stays neutral with regard to jurisdictional claims in published maps and institutional affiliations.

Copyright: (c) 2021 by the authors. Licensee MDPI, Basel, Switzerland. This article is an open access article distributed under the terms and conditions of the Creative Commons Attribution (CC BY) license (https:// creativecommons.org/licenses/by/ $4.0 /)$.

\begin{abstract}
In recent years, research has focused on phenolic compounds and their putative role as markers of graft incompatibility. Thus far, no studies have been conducted on the role of phenolic compounds in chestnut (Castanea spp.). The present study investigated the content of phenolic compounds in different combinations of Castanea spp. cultivars and rootstocks. Analyses were performed on the inner and outer tissues of chestnut grafts at two phenological sampling stages. The separation, identification and quantification of the phenolic markers via HPLC were preceded by an ultrasonic green extraction. Two chromatographic methods were tested for a total of 15 phenol compounds. Flavonol compounds were not detected, while cinnamic acids were found in low concentrations. The amount of gallic acid turned out to be higher at the graft union of the incompatible combination $\left(20.11 \pm 1.47 \mathrm{mg} / 100 \mathrm{~g}_{\mathrm{FW}}\right.$ vs. $\left.8.94 \pm 1.08 \mathrm{mg} / 100 \mathrm{~g}_{\mathrm{FW}}\right)$. The same pattern was observed for catechin $\left(15.79 \pm 1.83 \mathrm{mg} / 100 \mathrm{~g}_{\mathrm{FW}}\right.$ vs. $\left.9.63 \pm 1.98 \mathrm{mg} / 100 \mathrm{~g}_{\mathrm{FW}}\right)$. Differences in tannin concentrations seemed to be species-specific, and were apparently not related to graft incompatibility. The present work underlines the potential application of certain phenol compounds for the early prediction of graft incompatibility in Castanea spp.
\end{abstract}

Keywords: compatibility; polyphenols; grafting; propagation; clonal rootstocks; HPLC; green extraction; biochemical compounds

\section{Introduction}

In recent years, the comprehension of the grafting process has made great progress; however, graft incompatibility remains one of the major obstacles in woody plant breeding, and for the nursery industry. Successful grafting is a complex biochemical and structural process that begins with an initial wound response, followed by callus formation, leading to the creation of a continuous cambium and plasmodesmata, and the establishment of a functional vascular system between the two grafting partners [1]. The critical points where incompatibility can occur are many, primarily when the meristematic tissues of both the scion and rootstock fail to merge and build a new cambium connection [2]. Furthermore, the fact that the new vascular connections could not be well differentiated, or were weakly established, has been postulated as the main reason for incompatibility in woody plants [3,4]. In fact, graft incompatibility can induce the undergrowth or overgrowth of the scion, which can provide dysfunctions in water and nutrients' flow through the graft union, and can cause the wilting of the plant. Usually, it occurs at early stages, when vascular connections are forming, but it can also appear at the fruiting stage, when the plant has a high demand for water and nutrients [5]. 
Because this incompatibility can occur either at an early phase or after years, with the tree breaking at the union point, it causes severe economic damage. In order to avoid incompatibility, the graft partners often belong to the same genus, although the grafting of different species is also common in order to induce resistance to soil-borne pests and diseases, and to enhance the tolerance to abiotic stresses [6]. It is therefore necessary to identify experimental procedures that address whether a certain breed will be compatible or not. In recent years, investigation has focused on phenolic compounds and their putative role as markers of either compatible or incompatible grafts.

Phenolic compounds, the biosynthesis of which is triggered by wounding and infections, are produced and accumulated during the callusing phase. It seems that the quantitative and qualitative differences in the phenolic patterns between the scion and the rootstock can imply dysfunctions at the graft union in different fruit trees, which leads us to consider them as potential markers of graft compatibility or incompatibility [7-10]. As a matter of fact, these compounds can be used as markers of graft incompatibility at an early stage: it is known that in Vitis spp., gallic acid increases in the case of incompatible grafts, while ferulic acid decreases [10]. In Prunus armeniaca (L.) grafted on incompatible Prunus rootstocks, the amount of phenolic compounds is higher, and is generally associated with the formation of small cells in incompatible scion-rootstock combinations that did not form successful unions in vitro [7]. Moreover, in less compatible apricot scion-rootstock combinations, a higher level of flavanols like catechin and epicatechin was detected [7,11,12]. High concentrations of catechin and epicatechin were also measured in pear-quince incompatible grafts before the appearance of visible incompatibility symptoms [13]. While the role of phenolic compounds has been tested in Vitis spp., Prunus spp. and Pyrus communis (L.), no studies have been conducted on Castanea spp.

In the last few years, the cultivation of chestnut has been experiencing a revival phase, affirming itself as an important fruit crop, especially in the European area. This renewed interest in its cultivation has caused the shifting of its production from being extensive to intensive. In chestnut farming, grafting has proven to be a very successful and reliable method of asexual propagation. However, incompatibility can occur, especially between European species and hybrid rootstocks, which are the most utilized in the orchard industry [6,14]. Graft incompatibility has several causes, above all of which are some anatomical issues: it is known that the unusual fluted stem structure existing in several species can cause the misalignment of tissues between the scion and the rootstock, as well as a necrotic layer at the grafting point which will act as a barrier between the two partners. In incompatible grafts, a mass of parenchymatous tissue interrupts the normal vascular connection between the rootstock and scion; the interruption of cambial continuity was also observed, probably due to the proliferation of phloem fiber tissue. Eventually, the lack of winter hardiness, infection by chestnut blight at the union point, poor grafting techniques, and scion-rootstock genetic distance can also provoke graft failure [14]. As described above, a successful grafting also depends on biochemical and metabolic reactions between the two partners. It seems that peroxidases play a potential role in grafting, as these enzymes are involved in lignin formation and lignin-carbohydrate bonding [15]. Graft incompatibility in chestnut can be classified into 'early', if it is seen in the first two years, and 'late', if it occurs after at least 5-7 years [6].

The aim of this research was to investigate an innovative biochemical approach for the early prediction of graft incompatibility between different chestnut genotypes. In order to do this, it focused on identifying and measuring phenolic compounds at the graft union, below it and above it to find out whether a certain pattern in the phenolic production could be predictive of graft incompatibility. It is a procedure that requires routine HPLC analysis, and it can be performed in the first year of grafting, thus allowing us to determine the success a priori before visual symptoms occur. 


\section{Materials and Methods}

\subsection{Plant Material}

Scions of Castanea sativa (Mill.) and Castanea mollissima (B1.) were grafted onto different seed and clonal rootstocks of $C$. sativa, Castanea crenata $\times$ Castanea sativa and Castanea pumila (L.) Mill. Tissues from the grafting point, $5 \mathrm{~cm}$ above and $5 \mathrm{~cm}$ below it were collected at two phenological sampling stages: at the callusing time (CAL), 60 days after grafting, and at the end of the vegetative cycle (EVC), 255 days after grafting. Callus formation is an essential step for the graft development, but it is not enough to ensure its success. During this step, an intense production and accumulation of secondary metabolites occurs. Many studies have reported differences in phenol expression at this stage.

The plant material was collected at the Chestnut R\&D Center, Piemonte (Chiusa Pesio, Cuneo Province, Italy), and from Castellino Riccardo Vivai. The cultivars used for the experimentation were 'Marrone della Val Susa' (C. sativa), a valuable marrone type variety historically cultivated in the Piemonte Region, and 'Chushuhong', a Chinese cultivar (C. mollissima). Four grafting combinations were tested, having been chosen based on their known compatibility level, as summarized in Table 1 and described below:

i. $\quad$ Chinese cultivar 'Chushuhong' $\times$ Euro-Japanese hybrid seedling rootstock $(\mathrm{CH} \times$ s_EUJAP);

ii. European cultivar 'Marrone della Val Susa' $\times$ Euro-Japanese hybrid seedling rootstock obtained from a progeny field (MSUS $\times$ sp_EUJAP);

iii. European cultivar 'Marrone della Val Susa' $\times$ Euro-Japanese hybrid clonal rootstock 'Marsol CA07' (MSUS × c_EUJAP);

iv. European cultivar 'Marrone della Val Susa' $\times$ C. pumila seedling rootstock (MSUS $\times$ s_PUM).

Table 1. Grafting combinations tested and the known level of compatibility.

\begin{tabular}{cccc}
\hline Combination & Scion & Rootstock (Species) & Known Compatibility Level \\
\hline $\mathrm{CH} \times$ s_EUJAP & $\begin{array}{c}\text { 'Chushuhong' } \\
(\text { Castanea mollissima })\end{array}$ & $\begin{array}{c}\text { hybrid seedling } \\
(\text { C. crenata } \times \text { C. sativa })\end{array}$ & Incompatible \\
\hline MSUS $\times$ sp_EUJAP & $\begin{array}{c}\text { Marrone della Val Susa' } \\
(\text { Castanea sativa })\end{array}$ & $\begin{array}{c}\text { seedling progeny 'MB221' } \\
(\text { C. crenata } \times \text { C. sativa })\end{array}$ & compatible \\
\hline MSUS $\times$ c_EUJAP & $\begin{array}{c}\text { Marrone della Val Susa' } \\
(\text { Castanea sativa })\end{array}$ & $\begin{array}{c}\text { clonal 'Marsol CA07' } \\
(\text { C. crenata } \times \text { C. sativa })\end{array}$ & compatible \\
\hline MSUS $\times$ s_PUM & $\begin{array}{c}\text { Marrone della Val Susa' } \\
(\text { Castanea sativa })\end{array}$ & $\begin{array}{c}\text { Seedling } \\
(\text { C. pumila })\end{array}$ & unknown \\
\hline
\end{tabular}

Trees were grafted in 2021 with the whip graft technique, which is widely used on chestnut because it guarantees a structural resistance at the graft union point. Mastic was applied on the upper cut of the scion to avoid dehydration, and then a specific biodegradable grafting tape was used to bond the union point tightly.

For each graft combination and at each phenological stage, five plants were sampled and stored at $-80^{\circ} \mathrm{C}$ until the analytical analysis. Three small sections of $5 \mathrm{~cm}$ each were then obtained from every plant: one section above the graft (corresponding to the scion), one at the graft union, and one below the graft (corresponding to the rootstock).

Then, each section was cut longitudinally, and the bark and cortex were separated from the inner tissues. The outer and inner tissues were immediately frozen in liquid nitrogen and separately ground in a mortar. This step had to be performed very rapidly in order to avoid tissue oxidation and the hydrolysis process, which may modify the phenolic composition of the samples. For each section, the ground tissues derived from the five plants of each graft combination were then mixed, weighed and stored at $-80^{\circ} \mathrm{C}$ until extraction, as described in a previous study on Vitis spp. [16] 


\subsection{Extraction of the Polyphenolic Markers}

In this study, several phenolic compounds were considered, having been chosen from among those that were found to be more involved in the grafting process: 4 cinnamic acids (caffeic, chlorogenic, coumaric and ferulic acids), 5 flavonols (hyperoside, isoquercitrin, quercetin, quercitrin, rutin and ellagic acid), 2 benzoic acids (ellagic and gallic acids), 2 catechins (catechin, epicatechin) and 2 tannins (castalagin, vescalagin). A preliminary solvent extraction was performed: $1 \mathrm{~g}$ of the ground material was added to $20 \mathrm{~mL}$ of a mix of methanol, water and HCL (95:4.5:0.5, v:v:v) overnight. Then, the secondary metabolites were extracted by an ultrasonic bath for 30 min (Hielscher Ultrasonics UP200 St, Teltow, Germany). Later, each sample was centrifuged at $4000 \mathrm{rpm}$ for $10 \mathrm{~min}$, and then the liquid phase was filtered through a $0.45 \mu \mathrm{m}$ filter (polytetrafluoroethylene membrane-PTFE) and finally analysed by HPLC-DAD [17].

\subsection{Chromatographic Analysis}

The separation, identification, and quantification of the phenolic markers were performed by an Agilent 1200 HPLC (Agilent Technologies, Santa Clara, CA, USA) with manual injection $(20 \mu \mathrm{L}$ sample loop) coupled to an UV-Vis Diode Array Detector.

The chromatographic separation was performed on a Kinetex C18 column $(4.6 \times 150 \mathrm{~mm}$, $5 \mu \mathrm{m}$, Phenomenex, Torrance, CA, USA) [18].

The different procedures utilised in the analysis are described in the Supplementary Materials (including Table S1).

\subsection{Statistical Analysis}

Data were subjected to a one-factor ANOVA test (SPSS 22.0), and the mean values were compared with Tukey's HSD post-hoc comparison test at $p<0.05(n=3)$. The data are expressed as the mean value \pm standard deviation (SD). The significant statistical differences $(p<0.05)$ are highlighted by different letters according to the Tukey test.

\section{Results and Discussion}

The aim of the present work was to verify whether phenol compounds could be used as markers of graft compatibility in chestnut propagation, in order to forecast at a very early stage the grafting success rate. In this study, five classes of phenols-for a total of 15 bioactive compounds-were analysed: benzoic acids (ellagic and gallic acids), cinnamic acids (caffeic, chlorogenic, coumaric and ferulic acids), catechins (catechin and epicatechin), tannins (castalagin and vescalagin) and flavonols (hyperoside, isoquercitrin, quercetin, quercitrin and rutin). From all the sections analysed, the graft union allowed us to better discriminate the differences in terms of the expression of phenol compounds. In light of this consideration, the reported results focus on the graft union tissues.

The most represented bioactive class was tannins $(75.19 \%$ at CAL and $81.10 \%$ at EVC), followed by catechins $(21.21 \%$ and $16.20 \%)$, benzoic acids $(3.32 \%$ and $2.45 \%)$ and cinnamic acids $(0.27 \%$ and $0.25 \%)$. Compounds belonging to the flavonol class were not detected.

Although the discussion of the results deals with all of the phenols cited above, only a few compounds showed statistically significant differences between the compatible MSUS $\times$ c_EUJAP ('Marrone della Val Susa' grafted on clonal 'Marsol CA07') and incompatible $\mathrm{CH} \times$ s_EUJAP ('Chushuhong' $\times$ hybrid seedling) graft combinations, confirming what was found on fruit species such as Pyrus, Vitis and Prunus spp. Moreover, this is the first work that focused on the role of phenolic compounds in chestnut grafting, contributing to the improvement of the knowledge of this under-studied crop.

\subsection{Benzoic Acids}

Table 2 reports the concentration of benzoic acids found at the graft area for all of the combinations tested, as measured at CAL and EVC stages. 
Table 2. Benzoic acid fingerprint of the tissues at the graft union. The results are reported as mg of the bioactive compound per $100 \mathrm{~g}$ fresh weight (FW).

\begin{tabular}{|c|c|c|c|c|c|c|c|c|c|c|}
\hline \multirow[b]{2}{*}{ Phenological Stage } & \multirow[b]{2}{*}{ Bioactive Class } & \multirow[b]{2}{*}{ Compound } & \multicolumn{2}{|c|}{$\mathrm{CH} \times$ s_EUJAP } & \multicolumn{2}{|c|}{ MSUS $\times$ s_EUJAP } & \multicolumn{2}{|c|}{ MSUS × c_EUJAP } & \multicolumn{2}{|c|}{ MSUS × s_PUM } \\
\hline & & & $\begin{array}{c}\text { Mean Value } \\
\text { (mg/100 }\end{array}$ & SD & $\begin{array}{r}\text { Mean Valu } \\
\text { (mg/10c }\end{array}$ & SD & $\begin{array}{r}\text { Mean Valu } \\
(\mathrm{mg} / 10\end{array}$ & SD & $\begin{array}{r}\text { Mean Valu } \\
(\mathrm{mg} / 10\end{array}$ & SD \\
\hline \multirow{2}{*}{ Callusing } & \multirow{2}{*}{ Benzoic acids } & ellagic acid & $31.10 \mathrm{a}$ & 2.84 & $36.02 \mathrm{a}$ & 3.36 & $32.41 \mathrm{a}$ & 2.64 & $35.23 \mathrm{a}$ & 4.75 \\
\hline & & gallic acid & $20.11 \mathrm{c}$ & 1.47 & $11.40 \mathrm{ab}$ & 1.87 & $8.94 \mathrm{a}$ & 1.08 & $14.09 \mathrm{~b}$ & 1.19 \\
\hline \multirow{2}{*}{ End of vegetative cycle } & \multirow{2}{*}{ Benzoic acids } & ellagic acid & $24.63 \mathrm{a}$ & 3.71 & $28.62 \mathrm{a}$ & 4.64 & $26.10 \mathrm{a}$ & 2.18 & $27.17 \mathrm{a}$ & 2.56 \\
\hline & & gallic acid & $15.71 \mathrm{c}$ & 1.70 & $6.77 \mathrm{ab}$ & 1.55 & $5.58 \mathrm{a}$ & 1.57 & $11.55 \mathrm{bc}$ & 1.05 \\
\hline
\end{tabular}

The mean value and standard deviation are given for each sample $(n=3)$. Different letters for each compound indicate the significant differences at $p<0.05$.

According to the results, the concentration of gallic acid had a general pattern in all of the tested combinations, decreasing from CAL to the EVC. From the analysis of the amounts detected at CAL on the graft union tissues, clear and statistically significant differences emerged. The incompatible combination $\mathrm{CH} \times$ s_EUJAP recorded the statistically higher accumulation of this compound $(20.11 \pm 1.47 \mathrm{mg} / 100 \mathrm{~g}$ FW), followed by MSUS $\times$ s_PUM $\left(14.09 \pm 1.19 \mathrm{mg} / 100 \mathrm{~g}_{\mathrm{FW}}\right)$, the compatibility level of which is still unknown. The smallest quantities of gallic acid were found in MSUS $\times$ c_EUJAP $\left(8.94 \pm 1.08 \mathrm{mg} / 100 \mathrm{~g}_{\mathrm{FW}}\right)$, which were over two times lower than in the incompatible combination, and in MSUS $\times$ s_EUJAP $\left(11.40 \pm 1.87 \mathrm{mg} / 100 \mathrm{~g}_{\mathrm{FW}}\right)$, with both having a well-known affinity.

These data highlight a variability among the compatible combinations, depending on the origin of the rootstock: the concentration of gallic acid lightly increased in the seedling rootstock combination MSUS $\times$ s_EUJAP with respect to clonal rootstock MSUS $\times$ c_EUJAP, both at the CAL and EVC stages.

At the EVC stage, a decrease of the gallic acid amounts was recorded in all of the tested combinations. The higher quantity in the graft union tissues, as for the CAL stage, was found in $\mathrm{CH} \times$ s_EUJAP $\left(15.71 \pm 1.70 \mathrm{mg} / 100 \mathrm{~g}_{\mathrm{FW}}\right)$, followed by MSUS $\times$ s_PUM $\left(11.55 \pm 1.05 \mathrm{mg} / 100 \mathrm{~g}_{\mathrm{FW}}\right)$, which did not differ statistically from the incompatible combination. The compatible combinations showed the largest decrease of gallic acid, at $-40.61 \%$ for MSUS $\times$ s_EUJAP and $-37.58 \%$ for MSUS $\times$ c_EUJAP. The letter grafting combination had the statistically significant lower value $\left(5.58 \pm 1.57 \mathrm{mg} / 100 \mathrm{~g}_{\mathrm{FW}}\right)$.

These results are in accordance with previous work on apricot (Prunus armeniaca) establishing that gallic acid production is higher in less-compatible graft combinations, especially at early stages [9]. In Vitis spp., this acid proved to be a good marker of compatibility, as it was more abundant in less-compatible graft combinations [10,16,19]. As well as Vitis spp., a study on Eucalyptus gunni (Hook.f.) phenol composition showed a gallic acid peak in incompatible grafts [20]. In this study, in vitro plantlets of E. gunni were sampled at the grafting union, and gallic acid was quantified after 20 and 40 days after grafting. The amount of this acid decreased severely from 20 to 40 days in both the compatible and incompatible combinations, with the highest concentration being recorded at 20 days in the incompatible grafts. As suggested by many authors $[12,19,21]$, the higher amount of gallic acid at the graft union may be explained by its antioxidant power, which enhances the reductive state of the cells and confers tolerance to the oxidative stress that exists mainly at the graft union. Gallic acid is a benzoic acid normally produced under stress conditions, so it may be the mechanism through which the plant attempts to overcome the stress caused by the graft.

Ellagic acid and gallic acid had a similar pattern, with both decreasing from CAL to EVC, but in the case of ellagic acid, this decrease was less pronounced. Indeed, its concentration in all of the combinations shrank by about $20 \%$, following a pattern already observed on E. gunni, where this compound showed statistically significant differences among compatible and incompatible combinations [20]. This compound did not show any deep differences between compatible and incompatible combinations, leading us to think that it may not be a suitable marker of graft compatibility in chestnut.

Among the benzoic acids investigated, only gallic acid furnished positive results, supporting previous outcomes on fruit crops' graft incompatibility. 


\subsection{Cinnamic Acids}

Based on previous research findings, the content of caffeic, chlorogenic, coumaric and ferulic acids was measured. Indeed, previous works demonstrated that cinnamic acids could be involved in graft compatibility in Vitis spp. and P. communis [10,19,22]. Moreover, the effect of these compounds during the differentiation of vascular tissues on Olea europaea (L.) was investigated, and the results highlighted that ferulic acid had higher concentrations in grafting combinations that did not differentiate an intact and well-functioning vascular system [23].

The chestnut tissues analysed at the graft union for all of the combinations had very low amounts of cinnamic acids, in the range of $2 \mathrm{mg} / 100 \mathrm{~g}_{\mathrm{FW}}$, which seems to suggest that they may not be reliable markers of graft compatibility (Table 3 ).

Table 3. Cinnamic acid fingerprint of the tissues at the graft union. The results are reported as $\mathrm{mg}$ of the bioactive compound per $100 \mathrm{~g}$ fresh weight (FW).

\begin{tabular}{|c|c|c|c|c|c|c|c|c|c|c|}
\hline \multirow{3}{*}{ Phenological Stage } & \multirow{3}{*}{ Bioactive Class } & \multirow[b]{2}{*}{ Compound } & \multicolumn{2}{|l|}{$\mathrm{CH} \times \mathrm{s}$ EUIAP } & \multicolumn{2}{|c|}{ MSUS $\times$ s_EUJAP } & \multicolumn{2}{|c|}{ MSUS $\times$ c_EUJAP } & \multicolumn{2}{|c|}{ MSUS $\times$ s_PUM } \\
\hline & & & $\begin{array}{l}\text { Mean Value } \\
\quad\left(\mathrm{mg} / 100 \mathrm{~g}_{\mathrm{FW}}\right)\end{array}$ & SD & $\begin{array}{l}\text { Mean Value } \\
\quad\left(\mathrm{mg} / 100 \mathrm{~g}_{\mathrm{FW}}\right)\end{array}$ & SD & $\begin{array}{l}\text { Mean Value } \\
\quad\left(\mathrm{mg} / 100 \mathrm{~g}_{\mathrm{F}}\right.\end{array}$ & SD & $\begin{array}{l}\text { Mean Value } \\
\quad\left(\mathrm{mg} / 100 \mathrm{~g}_{\mathrm{FW}}\right.\end{array}$ & SD \\
\hline & & caffeic acid & $1.04 \mathrm{a}$ & 0.38 & $1.27 \mathrm{a}$ & 0.34 & $1.43 \mathrm{a}$ & 0.30 & $1.15 \mathrm{a}$ & 0.23 \\
\hline \multirow{4}{*}{ Callusing } & \multirow{3}{*}{ Cinnamic acids } & chlorogenic acid & $1.02 \mathrm{a}$ & 0.15 & $1.49 \mathrm{a}$ & 0.10 & $1.80 \mathrm{a}$ & 0.27 & $1.08 \mathrm{a}$ & 0.08 \\
\hline & & coumaric acid & n.d. & / & n.d. & / & n.d. & / & n.d. & / \\
\hline & & ferulic acid & $1.02 \mathrm{a}$ & 0.29 & $1.07 \mathrm{a}$ & 0.23 & $1.95 \mathrm{a}$ & 0.39 & $1.35 \mathrm{a}$ & 0.27 \\
\hline & & caffeic acid & $0.62 \mathrm{a}$ & 0.28 & $1.05 \mathrm{a}$ & 0.16 & $1.28 \mathrm{a}$ & 0.18 & $0.96 \mathrm{a}$ & 0.15 \\
\hline \multirow{3}{*}{ End of vegetative cycle } & \multirow{3}{*}{ Cinnamic acids } & chlorogenic acid & $1.22 \mathrm{a}$ & 0.14 & $2.28 \mathrm{a}$ & 0.26 & $2.37 \mathrm{a}$ & 0.25 & $1.25 \mathrm{a}$ & 0.19 \\
\hline & & coumaric acid & n.d. & / & n.d. & / & n.d. & / & n.d. & / \\
\hline & & ferulic acid & $0.46 \mathrm{a}$ & 0.06 & $1.00 \mathrm{a}$ & 0.10 & $1.64 \mathrm{a}$ & 0.18 & $0.74 \mathrm{a}$ & 0.14 \\
\hline
\end{tabular}

The mean value and standard deviation are given for each sample $(n=3)$. Different letters for each compound indicate significant differences at $p<0.05$. n.d.= not detected.

Caffeic and ferulic acids had a very similar trend, decreasing from CAL to EVC and showing the higher amount in the compatible combination MSUS $\times$ c_EUJAP (at CAL, the caffeic acid concentration was $1.43 \pm 0.30 \mathrm{mg} / 100 \mathrm{~g}_{\mathrm{FW}}$, while the ferulic acid quantity was $\left.1.95 \pm 0.39 \mathrm{mg} / 100 \mathrm{~g}_{\mathrm{FW}}\right)$. However, these slight differences did not differ from a statistical point of view. The similar trend and quantity which showed in the data may be due to the metabolic connection between these two phenol compounds, as ferulic acid derives from caffeic acid through the COMT enzyme [24].

In contrast to the ferulic and caffeic acid patterns, chlorogenic acid increased from CAL to EVC, and its concentration was slightly higher compared to the two previous compounds. At both phenological sampling stages, the chlorogenic acid level was higher in the compatible grafts, particularly in the ones grafted on clonal rootstock. At EVC, MSUS $\times$ c_EUJAP reached the maximum amount of $2.37 \pm 0.25 \mathrm{mg} / 100 \mathrm{~g}_{\mathrm{FW}}$, while a lower value of chlorogenic acid was detected in the incompatible combination $\mathrm{CH} \times \mathrm{s}$ _EUJAP $\left(1.22 \pm 0.14 \mathrm{mg} / 100 \mathrm{~g}_{\mathrm{FW}}\right)$, followed by MSUS $\times \mathrm{s}_{-} \mathrm{PUM}\left(1.25 \pm 0.19 \mathrm{mg} / 100 \mathrm{~g}_{\mathrm{FW}}\right)$. However, as for caffeic and ferulic acids, these differences did not have statistical relevance.

Coumaric acid was not detected by the HPLC in any of the chestnut samples, even though many studies reported an accumulation of this acid in incompatible grafting combinations of other tree species $[8,9,20]$.

The concentration of these three cinnamic acids at the graft point may be justified by the fact that these compounds are involved in the biosynthesis of lignin, and for that reason they are be required in huge amount at the union point, where the scion and rootstock must synthesize new lignin to complete the grafting process. In fact, ferulic and caffeic acids stabilize the cell wall and contribute to the improvement of the mechanical stability of the graft union and thereby the graft success [25]. Some authors have also suggested that under particularly stressful conditions, there could be crosstalk between the phenol pathway and the lignin pathway, and hence chlorogenic acid could be converged to the lignin biosynthesis process [24].

These experimental data establish that cinnamic acids are found in very poor concentration (around $2 \mathrm{mg} / 100 \mathrm{~g}_{\mathrm{FW}}$ ), and that it is not possible to evidence a clear and divergent pattern between compatible and less-compatible graft combinations. Therefore, these 
phenols might participate in the determination of graft incompatibility, but they cannot be considered reliable markers in the forecasting of graft success in Castanea spp. Although ferulic acid proved to be a reliable marker of compatibility in Vitis [10], it seems that it is not the same scenario in Castanea spp. These findings corroborate the importance of species relativity, and therefore the need to identify one or more markers which are specific for a certain genus or species.

\subsection{Catechins}

Among the phenols analysed in the literature as potential markers of graft incompatibility, catechin and epicatechin seem to be suitable indicators in several woody species. It seems that these compounds could have a role in hindering cambial connections between the cells of the scion and rootstock, affecting the callus formation and lignin biosynthesis [16].

In particular, with regard to catechin, an accumulation of this compound was found in incompatible grafting combinations at the graft union in Eucalyptus gunnii, Pyrus communis and Vitis spp. $[13,19,20]$, above the graft interface in Prunus armeniaca and Vitis spp. $[3,9,16]$, and below it in Pyrus communis grafted on different pear rootstocks [22].

The results of the present study on catechin and epicatechin accumulation showed a clear trend common to most of the other phenol compounds analysed, such as ellagic, gallic, ferulic and caffeic acids. Indeed, their concentration slightly decreased from CAL to EVC (Table 4). This pattern can be explained because of the higher oxidative environment that prevails in the first stages of graft formation. As these compounds have a well-known antioxidant function, their accumulation at callusing contributes to confer tolerance to oxidative stress to cells [12]. However, only the catechin concentration differed significantly between the compatible and incompatible combinations, recording the higher concentration at CAL in $\mathrm{CH} \times$ s_EUJAP $\left(15.79 \pm 1.83 \mathrm{mg} / 100 \mathrm{~g}_{\mathrm{FW}}\right)$ and the statistically lower concentration in the compatible combination MSUS $\times$ c_EUJAP $\left(9.63 \pm 1.98 \mathrm{mg} / 100 \mathrm{~g}_{\mathrm{FW}}\right)$.

Table 4. Catechin fingerprint of the tissues at the graft union. The results are reported as $\mathrm{mg}$ of bioactive compound per $100 \mathrm{~g}$ fresh weight (FW).

\begin{tabular}{|c|c|c|c|c|c|c|c|c|c|c|}
\hline \multirow[b]{2}{*}{ Phenological Stage } & \multirow[b]{2}{*}{ Bioactive Class } & \multirow[b]{2}{*}{ Compound } & \multicolumn{2}{|l|}{$\mathrm{CH} \times$ s_EUJAP } & \multicolumn{2}{|c|}{ MSUS $\times$ s_EUJAP } & \multicolumn{2}{|c|}{ MSUS $\times$ c_EUJAP } & \multicolumn{2}{|c|}{ MSUS $\times$ S_PUM } \\
\hline & & & $\begin{array}{l}\text { Mean Value } \\
\quad\left(\mathrm{mg} / 100 \mathrm{~g}_{\mathrm{FW}}\right)\end{array}$ & SD & $\begin{array}{r}\text { Mean Valu } \\
\text { (mg/100 }\end{array}$ & SD & $\begin{array}{r}\text { Mean Valu } \\
\text { (mg/100 }\end{array}$ & SD & $\begin{array}{r}\text { Mean Valu } \\
(\mathrm{mg} / 100\end{array}$ & SD \\
\hline \multirow{2}{*}{ Callusing } & \multirow[b]{2}{*}{ Catechins } & catechin & $15.79 \mathrm{~b}$ & 1.83 & $11.05 \mathrm{ab}$ & 1.39 & $9.63 a$ & 1.98 & $12.98 \mathrm{ab}$ & 1.92 \\
\hline & & epicatechin & $290.22 \mathrm{a}$ & 3.69 & $287.14 \mathrm{a}$ & 7.59 & $301.59 \mathrm{a}$ & 13.43 & $281.16 \mathrm{a}$ & 9.19 \\
\hline \multirow{2}{*}{ End of vegetative cycle } & \multirow{2}{*}{ Catechins } & catechin & $13.33 \mathrm{~b}$ & 2.10 & $9.30 \mathrm{ab}$ & 1.25 & $6.31 \mathrm{a}$ & 1.20 & $10.44 \mathrm{ab}$ & 1.14 \\
\hline & & epicatechin & $235.22 \mathrm{a}$ & 8.04 & $220.14 \mathrm{a}$ & 11.03 & $249.59 \mathrm{a}$ & 6.57 & $222.16 \mathrm{a}$ & 9.18 \\
\hline
\end{tabular}

The mean value and standard deviation are given for each sample $(n=3)$. Different letters for each compound indicate the significant differences at $p<0.05$.

Regarding the epicatechin expression at the graft union, the concentration of this compound was much higher if compared to catechin. However, no differences were detected for all of the combinations at the two sampling stages. Similar results were obtained by Assunção et al., 2016, on four grafting combinations of Vitis spp. [10]. In this study, the compatibility level among combinations did not influence the expression of epicatechin. On the contrary, statistically significant differences were detected among the grafting sections. Based on these findings, they concluded that epicatechin could be useful only as an auxiliary compound in grafting incompatibility evaluation.

\subsection{Tannins}

This class of secondary metabolites can be found in many species, although few studies have investigated their role in the grafting process. Tannins are involved in the response to wounding, increasing in content as a part of the plant's defense system when mechanical injuries occur through an upregulation of genes involved in their synthesis [26]. Moreover, previous research on sorghum [27] has demonstrated that an accumulation of tannins has negative effects on the proliferation of callus, limiting the formation of vascular tissues. 
Therefore, it seems that tannins could negatively impact healing processes on the long term, as in the case of grafting propagation.

As further confirmation of these findings, studies on the anatomical properties of Pinus radiata (D. Don.) grafts found an excessive tannin accumulation in incompatible unions, as indicated by bark tissues with abnormal dark stains [28].

The present study focused particularly on two compounds, castalagin and vescalagin, as the most representative molecules in chestnut tissues [29]. Indeed, a 2014 work on different bark samples of $C$. sativa pointed to vescalagin and castalagin as the most abundant compounds [30].

The results show a common trend for both of the compounds analysed (Table 5). In fact, the castalagin and vescalagin concentrations increased from the CAL to EVC stage. The higher increase in concentration was recorded in the incompatible combination $\mathrm{CH} \times$ s_EUJAP $(+14.3 \%$ castalagin, $+13.4 \%$ vescalagin $)$, followed by the compatible MSUS $\times$ c_EUJAP $(+13.78 \%$ castalagin, $13.16 \%$ vescalagin $)$. These results appear to contradict what was stated on Carya illinoinensis (Wangenh.) by Su et al., 2021 [26], where grafted plants revealed a decreasing trend of tannin content during graft union development.

Table 5. Tannin fingerprint of the tissues at the graft union. The results are reported as mg of bioactive compound per $100 \mathrm{~g}$ fresh weight (FW).

\begin{tabular}{|c|c|c|c|c|c|c|c|c|c|c|}
\hline \multirow[b]{2}{*}{ Phenological Stage } & \multirow[b]{2}{*}{ Bioactive Class } & \multirow[b]{2}{*}{ Compound } & \multicolumn{2}{|c|}{ CH $\times$ s_EUJAP } & \multicolumn{2}{|c|}{ MSUS $\times$ s_EUJAP } & \multicolumn{2}{|c|}{ MSUS $\times$ c_EUJAP } & \multicolumn{2}{|c|}{ MSUS $\times$ s_PUM } \\
\hline & & & $\begin{array}{r}\text { Mean Valu } \\
(\mathrm{mg} / 10\end{array}$ & SD & $\begin{array}{r}\text { Mean Valu } \\
\text { (mg/10 }\end{array}$ & SD & $\begin{array}{r}\text { Mean Valu } \\
\text { (mg/10 }\end{array}$ & SD & $\begin{array}{r}\text { Mean Valt } \\
(\mathrm{mg} / 10\end{array}$ & SD \\
\hline \multirow{2}{*}{ Callusing } & \multirow{2}{*}{ Tannins } & castalagin & $380.43 a$ & 13.95 & $468.06 \mathrm{bc}$ & 10.50 & $505.38 \mathrm{c}$ & 21.79 & $435.56 \mathrm{~b}$ & 17.72 \\
\hline & & vescalagin & $517.14 \mathrm{a}$ & 21.22 & $673.69 \mathrm{c}$ & 17.06 & $2.57 \mathrm{c}$ & 29. & $624.08 \mathrm{~b}$ & 19.43 \\
\hline \multirow{2}{*}{ End of vegetative cycle } & \multirow{2}{*}{ Tannins } & castalagin & 434 & 11.80 & $529.62 \mathrm{bc}$ & 9.89 & $575.00 \mathrm{c}$ & 23.01 & $485.53 \mathrm{~b}$ & 12.30 \\
\hline & & vescalagin & $586.57 \mathrm{a}$ & 18.76 & $749.72 \mathrm{c}$ & 15.96 & $772.42 \mathrm{c}$ & 22.44 & $705.23 \mathrm{~b}$ & 14.13 \\
\hline
\end{tabular}

The mean value and standard deviation are given for each sample $(n=3)$. Different letters for each compound indicate the significant differences at $p<0.05$.

It is known that the content of tannins is highly species-dependent. A study on Chinese (C. mollissima) and American (Castanea dentata (Marsh.) Borkh.) chestnuts investigated the constitutive levels of the two major groups of tannins, hydrolysable tannins and proanthocyanidins, revealing a higher concentration of these compounds in the stems of C. dentata [31].

The findings of the present study highlighted a great variability in the quantity of tannins among the combinations. These differences seem to be species-specific, and are not apparently related to graft incompatibility. In fact, the amount of castalagin and vescalagin increased during the vegetative cycle in all of the graft combinations, with almost the same growth rate.

Although tannins have great importance in many industrial sectors-such as animal feed, leather and food, and especially in wine production-the reason of their abundance in Castanea species is still unclear. This study highlighted a common trend for all of the grafting combinations tested. This concentration increase during the vegetative cycle may suggest that tannin production could be related to the biosynthesis of structural tissues such as lignin.

\section{Conclusions}

Chestnut cultivation is experiencing a revival phase, affirming itself as an important fruit crop worldwide. In consideration of the growing importance of this species, the breeding of new cultivars and rootstocks is very active. Grafting is the main technique used to propagate chestnut, though incompatibility represents a critical issue. Therefore, one or more techniques which are able to predict graft incompatibility early are needed, as for other valuable fruit crops.

The present work is the first that addresses the question on Castanea spp. from a biochemical point of view, focusing on the quali-quantitative expression of phenol compounds. In particular, the aim of the work was to find one or more phenol compounds that could work as markers for an early identification of incompatibility, before visual symptoms occur. 
In total, 15 bioactive compounds belonging to five phenol classes were chosen based on the literature, and their expression at different phenological periods and on different graft sections was analysed. The results are encouraging, supporting the hypothesis that some molecules are more suitable than others for the prediction of incompatibility phenomena. More specifically, the amount of gallic acid was over two times higher at the grafting union of incompatible combinations. The same trend was observed for catechin, with higher statistically significant values detected in incompatible grafts. The gallic acid at the graft union of incompatible combinations recorded an increase of $+125 \%$ at callusing and $+181 \%$ at the end of the vegetative cycle compared to the concentration of compatible ones. As for catechin, it increased by $+64 \%$ at the first sampling period, and by $+111 \%$ at the end of the vegetative season in incompatible grafts.

Some compounds did not seem to be suitable markers of incompatibility, such as cinnamic acids, which are present in very low quantities in chestnut tissues. Other molecules like ellagic acid and epicatechin, which turned out to be good markers on other fruit species, need further research. The same goes for castalagin and vescalagin, the concentrations of which largely differed among the tested combinations. These compounds increased in Castanea tissues throughout the vegetative cycle, showing a percentage increase of approximately $14 \%$ for both compatible and incompatible grafting combinations. This common increasing trend indicates that the differences in tannin concentrations could be species-specific, and apparently not related to graft incompatibility.

Future works addressing the issue will have to enlarge the number of rootstocks and cultivars tested in order to strengthen and validate the present findings.

Supplementary Materials: The following are available online at https:/ / www.mdpi.com/article/ 10.3390/horticulturae8010032/s1. Table S1: Conditions of the methods used for the chromatographic analysis.

Author Contributions: Conceptualization, G.G., D.D. and G.L.B.; Data curation, G.G. and D.D.; Formal analysis, G.G. and D.D.; Investigation, G.G. and V.C.; Methodology, G.G. and D.D.; Resources, G.G. and D.D.; Supervision, G.L.B.; Validation, D.D., Z.R.R. and G.L.B.; Writing-original draft, G.G. and V.C.; Writing-review and editing, Z.R.R. and G.L.B. All authors have read and agreed to the published version of the manuscript.

Funding: This research has not received external funding.

Institutional Review Board Statement: Not applicable.

Informed Consent Statement: Not applicable.

Acknowledgments: The authors would like to thank Mauro Caviglione and Marco D'Oria for the helpfulness and professionalism with which they grafted all of the chestnut combinations.

Conflicts of Interest: The authors declare no conflict of interest.

\section{References}

1. Milien, M.; Renault-Spilmont, A.-S.; Cookson, S.J.; Sarrazin, A.; Verdeil, J.-L. Visualization of the 3D structure of the graft union of grapevine using X-ray tomography. Sci. Hortic. 2012, 144, 130-140. [CrossRef]

2. Pina, A.; Errea, P. A review of new advances in mechanism of graft compatibility-incompatibility. Sci. Hortic. 2005, 106, 1-11. [CrossRef]

3. Errea, P.; Felipe, A.; Herrero, M. Graft establishment between compatible and incompatible Prunus spp. J. Exp. Bot. 1994, 45, 393-401. [CrossRef]

4. Mosse, B. Graft-Incompatibility in Fruit Trees; Commonwealth Agricultural Bureaux: Farnham Royal, UK, 1962.

5. $\quad$ Davis, A.R.; Perkins-Veazie, P.; Sakata, Y.; Lopez-Galarza, S.; Maroto, J.V.; Lee, S.-G.; Huh, Y.-C.; Sun, Z.; Miguel, A.; King, S.R. Cucurbit grafting. Crit. Rev. Plant Sci. 2008, 27, 50-74. [CrossRef]

6. Beccaro, G.; Alma, A.; Bounous, G.; Gomes-Laranjo, J. The Chestnut Handbook: Crop E Forest Management; CRC Press: Boca Raton, FL, USA, 2019.

7. Errea, P.; Garay, L.; Marín, J.A. Early detection of graft incompatibility in apricot (Prunus armeniaca) using in vitro techniques. Physiol. Plant. 2001, 112, 135-141. [CrossRef] 
8. Mng'omba, S.A.; du Toit, E.S.; Akinnifesi, F.K. The relationship between graft incompatibility and phenols in Uapaca kirkiana Müell Arg. Sci. Hortic. 2008, 117, 212-218. [CrossRef]

9. Usenik, V.; Krška, B.; Vičan, M.; Štampar, F. Early detection of graft incompatibility in apricot (Prunus armeniaca L.) using phenol analyses. Sci. Hortic. 2006, 109, 332-338. [CrossRef]

10. Assunção, M.; Canas, S.; Cruz, S.; Brazão, J.; Zanol, G.C.; Eiras-Dias, J. Graft compatibility of Vitis spp.: The role of phenolic acids and flavanols. Sci. Hortic. 2016, 207, 140-145. [CrossRef]

11. Errea, P.; Treutter, D.; Feucht, W. Specificity of individual flavan-3-ols interfering with the grafting stress of apricots. Angew. Bot. 1992, 66, 21-24.

12. Errea, P.; Feucht, W.; Gutmann, M. Physiological implications of flavan-3-ols in apricot-rootstock combinations. Adv. Hortic. Sci. 2000, 14, 1000-1009.

13. Musacchi, S.; Pagliuca, G.; Kindt, M.; Piretti, M.V.; Sansavini, S. Flavonoids as markers for pear-quince graft incompatibility. J. Appl. Bot. 2000, 74, 206-211.

14. Huang, H.; Norton, J.; Boyhan, G.; Abrahams, B. Graft compatibility among chestnut (Castanea) species. J. Am. Soc. Hortic. Sci. 1994, 119, 1127-1132. [CrossRef]

15. Santamour Jr, F.; McArdle, A.; Jaynes, R. Cambial isoperoxidase patterns in Castanea. J. Environ. Hortic. 1986, 4, 14-16. [CrossRef]

16. Canas, S.; Assunção, M.; Brazão, J.; Zanol, G.; Eiras-Dias, J.E. Phenolic compounds involved in grafting incompatibility of Vitis spp.: Development and validation of an analytical method for their quantification. Phytochem. Anal. 2015, 26, 1-7. [CrossRef] [PubMed]

17. Donno, D.; Turrini, F.; Boggia, R.; Guido, M.; Gamba, G.; Mellano, M.G.; Riondato, I.; Beccaro, G.L. Vitis vinifera L. Pruning Waste for Bud-Preparations as Source of Phenolic Compounds-Traditional and Innovative Extraction Techniques to Produce New Natural Products. Plants 2021, 10, 2233. [CrossRef]

18. Gamba, G.; Donno, D.; Mellano, M.G.; Riondato, I.; De Biaggi, M.; Randriamampionona, D.; Beccaro, G.L. Phytochemical characterization and bioactivity evaluation of autumn olive (Elaeagnus umbellata Thunb.) pseudodrupes as potential sources of health-promoting compounds. Appl. Sci. 2020, 10, 4354. [CrossRef]

19. Assunção, M.; Pinheiro, J.; Cruz, S.; Brazão, J.; Queiroz, J.; Dias, J.E.E.; Canas, S. Gallic acid, sinapic acid and catechin as potential chemical markers of Vitis graft success. Sci. Hortic. 2019, 246, 129-135. [CrossRef]

20. Cooman, L.D.; Everaert, E.; Curir, P.; Dolci, M. The possible role of phenolics in incompatibility expression in Eucalyptus gunnii micrografts. Phytochem. Anal. 1996, 7, 92-96. [CrossRef]

21. Rice-Evans, C.A.; Miller, N.J.; Paganga, G. Structure-antioxidant activity relationships of flavonoids and phenolic acids. Free Radic. Biol. Med. 1996, 20, 933-956. [CrossRef]

22. Hudina, M.; Orazem, P.; Jakopic, J.; Stampar, F. The phenolic content and its involvement in the graft incompatibility process of various pear rootstocks (Pyrus communis L.). J. Plant Physiol. 2014, 171, 76-84. [CrossRef]

23. Azimi, M.; Ozkaya, M.T.; Colgecen, H.; Buyukkartal, H.N. Analysis of phenolic compounds for determination of cambium differentiation and tracheal elements in olive graft combinations. J. Exp. Biol. Agric. Sci. 2016, 4, 714-720.

24. De Silva, N.V.; Mazzafera, P.; Cesarino, I. Should I stay or should I go: Are chlorogenic acids mobilized towards lignin biosynthesis? Phytochemistry 2019, 166, 112063. [CrossRef] [PubMed]

25. Boerjan, W.; Ralph, J.; Baucher, M. Lignin biosynthesis. Annu. Rev. Plant Biol. 2003, 54, 519-546. [CrossRef]

26. Su, W.; He, H.; Liu, Z.; Mo, Z.; Cao, F.; Peng, F. Physiological and biochemical changes during graft union formation in Carya illinoinensis. Biol. Plant. 2021, 65, 203-211. [CrossRef]

27. Kuriyama, T.; Shimada, S.; Matsui, M. Improvement of Agrobacterium-mediated transformation for tannin-producing sorghum. Plant Biotechnol. 2019, 36, 43-48. [CrossRef] [PubMed]

28. Copes, D.L. Development of internal graft incompatibility symptoms in Pinus radiata D. Don. N. Z. J. For. Sci. 1980, 10, 367-380.

29. Ricci, A.; Lagel, M.-C.; Parpinello, G.; Pizzi, A.; Kilmartin, P.; Versari, A. Spectroscopy analysis of phenolic and sugar patterns in a food grade chestnut tannin. Food Chem. 2016, 203, 425-429. [CrossRef]

30. Comandini, P.; Lerma-García, M.J.; Simó-Alfonso, E.F.; Toschi, T.G. Tannin analysis of chestnut bark samples (Castanea sativa Mill.) by HPLC-DAD-MS. Food Chem. 2014, 157, 290-295. [CrossRef] [PubMed]

31. Cooper, W.R.; Rieske, L.K. Differential responses in American (Castanea dentata Marshall) and Chinese (C. mollissima Blume) chestnut (Falales: Fagaceae) to foliar application of jasmonic acid. Chemoecology 2008, 18, 121-127. [CrossRef] 